\title{
Multiple-Injection Capillary Zone Electrophoresis as a Fast Strategy to Determine Antinitrosating Capacity of Commercial Teas
}

\author{
Ana P. Ruani, ${ }^{a}$ Luciano Vitali ${ }^{a}$ and Gustavo A. Micke ${ }^{* a}$ \\ ${ }^{a}$ Departamento de Química, Universidade Federal de Santa Catarina, \\ 88040-900 Florianópolis-SC, Brazil
}

\begin{abstract}
This paper describes the use of a multiple-injection capillary electrophoresis method as a fast strategy to determine the antinitrosating capacity of nine commercial teas through nitrite quantification. The method consists of the injection of the sample followed by the injection of the control solution, employing a fused-silica capillary of $32.0 \mathrm{~cm}$ total length $(23.5 \mathrm{~cm}$ effective length, $50 \mu \mathrm{m}$ internal diameter) with background electrolyte composed of $4.0 \mathrm{~g} \mathrm{~L}^{-1} \beta$-alanine and $1.5 \mathrm{~g} \mathrm{~L}^{-1}$ perchloric acid ( $\mathrm{pH} 3.79$ ) and sodium thiocyanate was used as the internal standard. Before the injections the tea samples were maintained by $1 \mathrm{~h}$ of incubation, at $37^{\circ} \mathrm{C}$, with sodium nitrite in perchloric acid medium ( $\mathrm{pH} 2.3$ ). In order to avoid nitrite oxidation and nitrate formation, ultra-pure nearly oxygen-free water was used to prepare the solutions. Black tea, green tea and white tea, obtained from Camellia sinensis, showed greater antinitrosating capacity $(96,93$ and $89 \%$, respectively).
\end{abstract}

Keywords: multiple-injection, capillary electrophoresis, antinitrosating

\section{Introduction}

Nitrite is an important food additive, improving the color and flavor of meat products ${ }^{1,2}$ and suppressing the growth of microorganisms. ${ }^{3}$ However, under acid conditions, nitrite can be converted to nitrous acid, generating $\mathrm{N}_{2} \mathrm{O}_{3}$, which reacts with secondary amines to produce carcinogenic nitrosamines. ${ }^{4,5}$ We also highlight that dietary nitrite, as also nitrate, can be positively associated to type 1 diabetes and cancer risk, ${ }^{6,7}$ specifically to adult glioma and thyroid cancer risk. Xie et al. ${ }^{7}$ highlight that animal products are the main sources of dietary nitrite when compared with plant source products. Honikel ${ }^{8}$ reported, based in the European Parliament and Council Directive 95/2/EC, ${ }^{9}$ a range of added nitrite in meat products of $80-100 \mathrm{mg} \mathrm{kg}^{-1}$ and a range of $27-115 \mathrm{mg} \mathrm{kg}^{-1}$ residual amounts of nitrite (expressed as $\mathrm{NO}_{2}^{-}$). A study conducted by Lee ${ }^{10}$ pointed out the dietary exposures of nitrite for the U.S. population aged 2 years and older, and children aged 2 to 5 years, ranging 0.001-1.23 and 0.001-0.96 mg per person per day, respectively. Since animal products also contain amines and amides, known as nitrosamines precursors, they may result in more substantial exposure to carcinogenic $N$-nitroso compounds. According to DellaValle et al., ${ }^{11}$ vitamin $\mathrm{C}$

*e-mail: gustavo.micke@ufsc.br and other antioxidants can inhibit $N$-nitroso compounds formation associated to nitrosation reactions.

The generation of nitrosating species from nitrous acid has been described by several authors. ${ }^{2,12,13}$ Positively charged nitrogen oxide is the most powerful nitrosating species, found at acidic $\mathrm{pH}$ in nitrosonium $\left(\mathrm{NO}^{+}\right)$and nitrous acidium $\left(\mathrm{H}_{2} \mathrm{ONO}^{+}\right)$forms (equations 1 and 2 ).

$$
\begin{aligned}
& \mathrm{HNO}_{2}+\mathrm{H}_{3} \mathrm{O}^{+} \rightleftharpoons \mathrm{NO}^{+}+\mathrm{H}_{2} \mathrm{O} \\
& \mathrm{HNO}_{2}+\mathrm{H}_{3} \mathrm{O}^{+} \rightleftharpoons \mathrm{H}_{2} \mathrm{ONO}^{+}+\mathrm{H}_{2} \mathrm{O}
\end{aligned}
$$

However, dinitrogen trioxide $\left(\mathrm{N}_{2} \mathrm{O}_{3}\right)$, generated from nitrous acid in equilibrium (equation 3 ), is also a powerful nitrosating species and is the major reactive species at higher $\mathrm{pH}(5.5-6.5) .^{12,14}$

$2 \mathrm{HNO}_{2} \rightleftharpoons \mathrm{N}_{2} \mathrm{O}_{3}+\mathrm{H}_{2} \mathrm{O}$

Based on previous studies, ${ }^{15,16}$ Sebranek and Fox Jr. ${ }^{12}$ and Williams ${ }^{14}$ listed $\mathrm{NOCl}$ and $\mathrm{N}_{2} \mathrm{O}_{4}$ as nitrosating species under specific conditions, such as medium composition and temperature. Dinitrogen tetroxide $\left(\mathrm{N}_{2} \mathrm{O}_{4}\right)$ is a gas formed by nitrogen dioxide dimerization (equation 4 ), which promotes nitrosation or nitration of amides, depending on the tautomers formed..$^{15,17}$ 
$2 \mathrm{NO}_{2} \rightleftharpoons \mathrm{N}_{2} \mathrm{O}_{4}$

Dinitrogen trioxide dissociates into nitric oxide and nitrogen dioxide (equation 5), ${ }^{14,18}$ which is relevant to the formation of dinitrogen tetroxide and the oxidation of nitric oxide to nitrous acid (equation 6). ${ }^{19}$ Nitrous acid can also be restored by $\mathrm{N}_{2} \mathrm{O}_{4}$ hydrolysis (equation 7). ${ }^{2,20}$

$$
\begin{aligned}
& \mathrm{N}_{2} \mathrm{O}_{3} \rightleftharpoons \mathrm{NO}+\mathrm{NO}_{2} \\
& 4 \mathrm{NO}+\mathrm{O}_{2}+6 \mathrm{H}_{2} \mathrm{O} \rightarrow 4 \mathrm{NO}_{2}^{-}+4 \mathrm{H}_{3} \mathrm{O}^{+} \\
& \mathrm{N}_{2} \mathrm{O}_{4}+2 \mathrm{H}_{2} \mathrm{O} \rightleftharpoons \mathrm{HNO}_{2}+\mathrm{NO}_{3}^{-}+\mathrm{H}_{3} \mathrm{O}^{+}
\end{aligned}
$$

Dietary constituents, including flavonoids, ${ }^{21,22}$ proteins and amino acids, ${ }^{23}$ caffeic acid and derivatives, ${ }^{24}$ green tea polyphenols and $\alpha$-tocopherol, ${ }^{25}$ as well as strawberries, garlic juice and kale juice, ${ }^{26}$ exhibit antinitrosating capacity (AC), which can prevent nitrosamine formation and reduce the risk of cancer and chronic diseases. ${ }^{21}$

$\mathrm{AC}$ is mostly determined by the Griess reaction, ${ }^{27}$ through the addition of sulfanilic acid and naphthylethylenediamine to a nitrite solution under acid conditions, generating an azo dye. The reaction requires a 15 min incubation time and the spectrophotometric measurements are taken at $520 \mathrm{~nm} .^{21,27}$ Nitrite determination through Griess reagent requires an additional reaction step to generate the azo dye, ${ }^{27}$ as mentioned, although requires a simple spectrophotometric equipment and presents good sensitivity. This procedure can be adapted to different available equipment, such as microfluidic paper-based analytical devices as studied by Bhakta et al. ${ }^{28}$ Electrochemical detection and chromatographic methods can also be applied to quantify nitrite. ${ }^{29}$ Merino et $a l .^{2}$ describe that characteristics as selectivity, limit of detection (LOD), precision and costs can be considered to choose the most suitable method for the nitrite determination. Available capillary electrophoresis equipment allows the direct nitrite quantification with several advantages, including fully automation, fast analysis and small samples requirement, avoiding the Griess reaction step. ${ }^{30}$ Through the multiple-injection strategy, samples are consecutively injected into the capillary and analyzed in a single run, reducing the analysis time per sample..$^{31,32}$ Amini et $a l .^{33}$ described four modes of multiple-injection capillary zone electrophoresis (MICZE), whereas the methods used by our group involve two injection modes, MICZE mode I and MICZE mode II. These modes are referred to as the MISER (multiple-injection in a single experimental run) mode and the multiplex MISER (MP-MISER) mode, respectively. The first MISER mode allows the analysis of each injected sample in different regions of the electropherogram. In the MP-MISER mode, the electropherogram shows the intercalation of peaks.

Commercial teas are widely consumed and present several beneficial effects, including antioxidant properties. ${ }^{34,35}$ We studied the AC of several commercial teas by MISER monitoring the magnitude of the nitrite peak. Nitrate was also monitored in the method because it is a product of the antinitrosating reactions (more details in the Results and Discussion section, Antinitrosating capacity sub-section). This approach involves fast analysis and provides useful information about the health benefits of teas.

\section{Experimental}

\section{Chemicals and reagents}

Perchloric acid (65\%) and $\beta$-alanine (99\%) were purchased from Sigma Chemical Co. (St. Louis, MO, USA). Sodium nitrite, sodium nitrate and sodium thiocyanate were purchased from Merck (Darmstadt, Germany). All solutions were prepared daily using deionized water (Milli-Q, Millipore, Bedford, MA, USA). Tea samples were commercially obtained. Green tea was obtained from leaves and shoots of Camellia sinensis (lot No. 11/16), black tea was obtained from leaves and stems of Camellia sinensis (lot No. 667) and white tea was obtained from leaves and stems of Camellia sinensis (lot No. 735357). Strawberry tea was obtained from fruits of Fragaria spp., fruits of Pyrus malus, flowers of Hibiscus sabdariffa, fruits and flowers of Rosa canina and leaves of Stevia rebaudiana (lot No. 658). Detox tea was obtained from leaves of Baccharis genistelloides, fruits of Prunus domestica, fruits of Rubus spp., flowers of Hibiscus sabdariffa and flowers of Matricaria recutita (lot No. 04/17). Chamomile tea was obtained from flowers of Matricaria recutita (lot No. 03/17), fennel tea was obtained from fruits of Foeniculum vulgare (lot No. 01/17), mint tea was obtained from leaves and stems of Mentha piperita (lot No. 707) and boldo tea was obtained from leaves of Peumus boldus (lot No. 1409).

\section{Electrophoretic conditions}

Electrophoretic analyses were carried out on an Agilent HP 3D Capillary Electrophoresis system with a UV-Vis diode-array detector set at $200 \mathrm{~nm}$. Separations were performed in a fused-silica capillary of $32.0 \mathrm{~cm}(50 \mu \mathrm{m}$ i.d.) with an effective length of $23.5 \mathrm{~cm}$ and set at $25^{\circ} \mathrm{C}$. Electrophoretic separation was conducted using $4.0 \mathrm{~g} \mathrm{~L}^{-1}$ $\beta$-alanine and $1.5 \mathrm{~g} \mathrm{~L}^{-1}$ perchloric acid $(\mathrm{pH} 3.79)$ as the background electrolyte (BGE) and a separation voltage of $-30 \mathrm{kV}$. 
Initially, the capillary was flushed with $40.0 \mathrm{~g} \mathrm{~L}^{-1}$ of sodium hydroxide (30 $\mathrm{min})$, deionized water $(30 \mathrm{~min}$ ) and BGE (20 min). At the beginning of each day, the capillary was rinsed with $40.0 \mathrm{~g} \mathrm{~L}^{-1} \mathrm{NaOH}$ (5 min), water (5 min) and BGE (10 min). Between runs the capillary was flushed with BGE for $0.5 \mathrm{~min}$. At the end of each day, it was flushed with $40.0 \mathrm{~g} \mathrm{~L}^{-1} \mathrm{NaOH}(5 \mathrm{~min})$ and water $(5 \mathrm{~min})$.

Samples were introduced applying the following hydrodynamic pressures: $50 \mathrm{mbar} / 5 \mathrm{~s}$ (sample solution), $50 \mathrm{mbar} / 26 \mathrm{~s}$ (BGE plug) and $50 \mathrm{mbar} / 5 \mathrm{~s}$ (control solution).

\section{Sample preparation}

The samples of green, black, white, strawberry, detox, chamomile, fennel, mint and boldo teas analyzed in this study were obtained commercially. Two samples were prepared for each type of tea by the infusion of $25 \mathrm{~g}$ of dried material in $200 \mathrm{~mL}$ of boiling deionized water for $5 \mathrm{~min}$ (according to the manufacturer's instructions). Each sample was diluted by factors of 1:1 and 1:3 in deionized water. Sodium nitrite and perchloric acid solutions were prepared with almost oxygen-free water. The dissolved oxygen was partially removed by boiling deionized water for $15 \mathrm{~min}$ and purging this water with nitrogen for $15 \mathrm{~min}$.

\section{Antinitrosating capacity}

The AC of the commercial teas was determined based on the work of Liu et al. ${ }^{21}$ and Choi et al. ${ }^{22}$ Briefly, $350 \mu \mathrm{L}$ of the tea samples, in three different dilutions (1:0;1:1 and 1:3), was added to $350 \mu \mathrm{L}$ of $1.5 \mathrm{~g} \mathrm{~L}^{-1}$ perchloric acid and $350 \mu \mathrm{L}$ of $100 \mathrm{mg} \mathrm{L}^{-1}$ sodium nitrite (final concentration of $33.0 \mathrm{mg} \mathrm{L}^{-1}$ ). To obtain the control solution, the sodium nitrite solution was substituted by $350 \mu \mathrm{L}$ of nearly oxygen-free water. All samples were incubated for $1 \mathrm{~h}(\mathrm{pH} 2.3)$, in amber vials, at $37^{\circ} \mathrm{C}$. After the incubation period, $100 \mu \mathrm{L}$ of $8.0 \mathrm{~g} \mathrm{~L}^{-1}$ $\beta$-alanine was added to $300 \mu \mathrm{L}$ of the sample and control reaction solutions. Sodium thiocyanate (final concentration of $12.0 \mathrm{mg} \mathrm{L}^{-1}$ ) was used as the internal standard (IS). The AC (in percentage) was calculated from the following equation:

$$
\mathrm{AC}(\%)=\left[1-\frac{\mathrm{P}_{\mathrm{s}}}{\mathrm{P}_{\mathrm{c}}}\right] 100
$$

where $\mathrm{P}_{\mathrm{s}}$ is the corrected peak area for nitrite (sample) and $\mathrm{P}_{\mathrm{c}}$ is the corrected peak area for nitrite (control).

\section{Statistical analysis}

All results are expressed as the mean \pm standard deviation of four samples that were analyzed in triplicate.

\section{Results and Discussion}

\section{Method development}

The method was developed as described by Spudeit et al. ${ }^{36}$ following four steps. Firstly, a curve of the effective mobility as a function of the $\mathrm{pH}$ was constructed for each analyte (nitrite and nitrate) and the IS (thiocyanate). Secondly, the optimal $\mathrm{pH}$ value was determined according to the maximum separation and it was found to be in the range of 3.5-4.0. At this $\mathrm{pH}$, nitrite is not fully dissociated and its mobility is reduced. ${ }^{37,38}$ According to Vitali et al., ${ }^{39}$ in this $\mathrm{pH}$ range, the electroosmotic flow (EOF) mobility is low and a counter-electroosmotic mode can be used since the mobilities of the analytes are higher than the EOF mobility. Thirdly, an appropriate background electrolyte was selected based on the work of Della Betta et al., ${ }^{37}$ using perchlorate as the co-ion since its mobility is similar to those of the analytes, minimizing the peak asymmetry. According to Spudeit et al.,${ }^{36}$ co-ion parameter is the first procedure in BGE selection. $\beta$-Alanine was chosen as the counter-ion due to its $\mathrm{p} K_{\mathrm{a}}$ value (3.43) and buffering capacity. The separation conditions were predicted using the PeakMaster 5.3 software, ${ }^{40}$ which allowed the definition of the electrolyte composition as $4.0 \mathrm{~g} \mathrm{~L}^{-1} \beta$-alanine and $1.5 \mathrm{~g} \mathrm{~L}^{-1}$ perchloric acid at $\mathrm{pH} 3.79$. The mobility value of thiocyanate is close to that of the mobilities of the analytes and this was employed as the IS.

In order to decrease the total analysis time (TAT), the multiple-injection mode was used, allowing the injection of two different samples within a single run. Based on single injection parameters (migration time of the analytes and migration time difference), two multiple-injection modes were applied; firstly, a multiplexed MISER (MP-MISER) injection provided an improvement in the analysis, decreasing the total time per sample by $31.1 \%$. However, the results also showed an expected decrease in the performance after a few injections (normally after 8 injections). Secondly, the MISER injection mode was more reproducible than MP-MISER mode and it was chosen, in this study, to analyze sample and control solutions on the same electropherogram, which allowed the determination of the $\mathrm{AC}$ in a single run (Figure 1).

\section{Parameters of merit}

In order to evaluate the method performance for nitrite determination, the parameters linearity, precision, LOD, limit of quantification (LOQ), repeatability (instrumental, intra-day and inter-day precision) and selectivity were analyzed and the results are given in Table 1. The calibration 
(a)

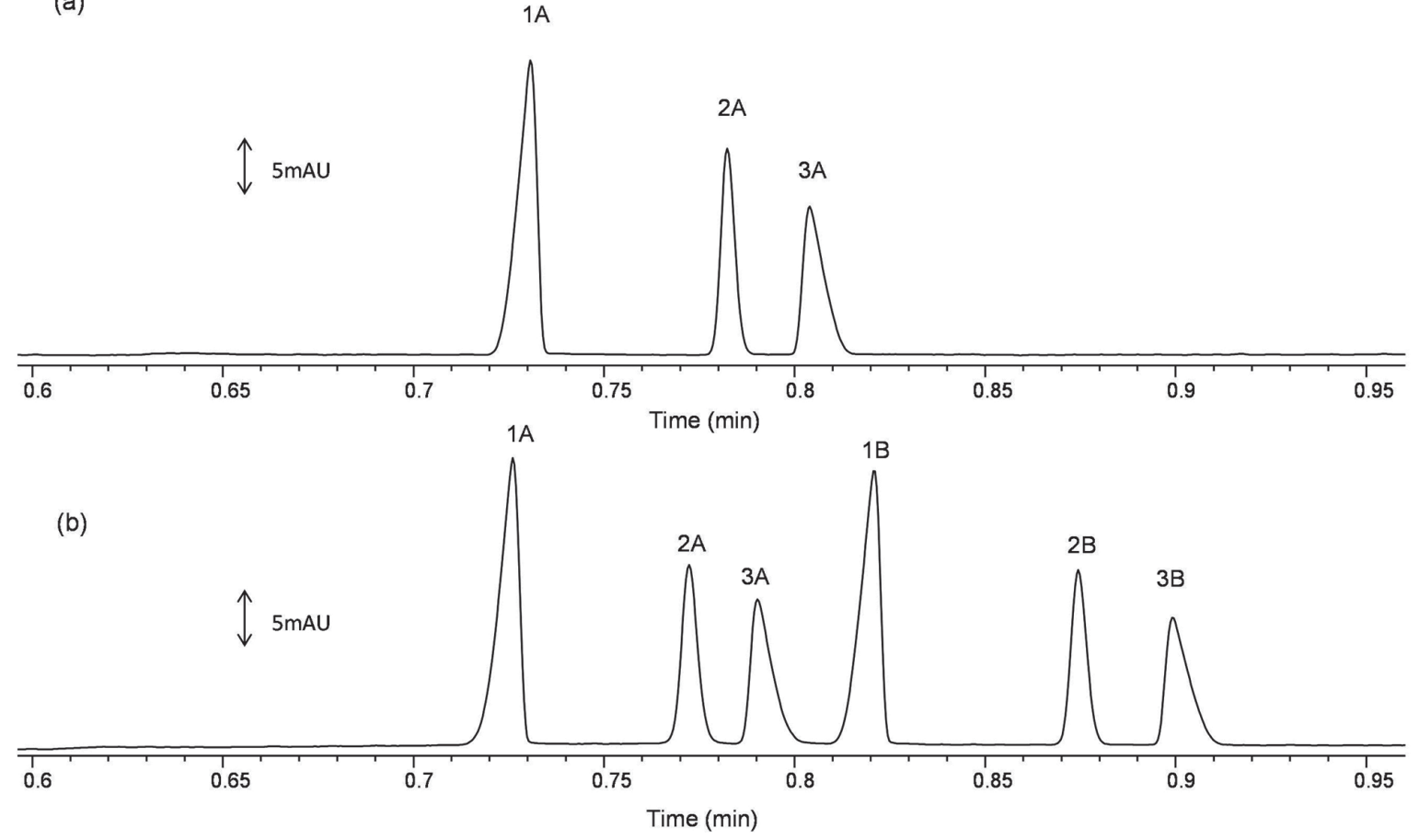

Figure 1. Comparison of single injection (a) and MISER injection (b) for a standard solution (final concentration $20.0 \mathrm{mg} \mathrm{L}^{-1}$ ). Peaks: 1: nitrate; 2: thiocyanate (IS); 3: nitrite; A and B represent the first (sample) and second (control) injections, respectively. Experimental conditions: capillary $32.0 \mathrm{~cm}$ (effective length $23.5 \mathrm{~cm}$ ) $\times 50 \mu \mathrm{m}$; BGE $4.0 \mathrm{~g} \mathrm{~L}^{-1} \beta$-alanine and $1.5 \mathrm{~g} \mathrm{~L}^{-1}$ perchloric acid, at $\mathrm{pH} 3.79$, voltage $-30 \mathrm{kV}, 25^{\circ} \mathrm{C}$.

curve for nitrite showed a coefficient of determination higher than 0.99. The precision results were better than $2.21 \%$ (intra-day) for peak area and $0.71 \%$ (inter-day) for peak corrected migration time.

\section{Antinitrosating capacity}

Previous reports have shown that $\mathrm{AC}$ is the greatest at acidic $\mathrm{pH}$ values, such as $\mathrm{pH} 2.5$ and 3.0. ${ }^{21,41}$ Mirvish $^{42}$ reported that the optimum $\mathrm{pH}$ for the nitrosation reaction is between 2.0 and 3.4, where nitrite is converted to nitrous acid and subsequently to active nitrosating species, as highlighted below.

The AC of nine commercial teas was determined at $\mathrm{pH}$ 2.3. At this $\mathrm{pH}$ value, nitrite is mostly converted (88\%, according to PeakMaster 5.3 software) to nitrous acid $\left(\mathrm{p} K_{\mathrm{a}} 3.22\right)$, considering the following equilibrium:

$\mathrm{HNO}_{2}+\mathrm{H}_{2} \mathrm{O} \rightleftharpoons \mathrm{NO}_{2}^{-}+\mathrm{H}_{3} \mathrm{O}^{+}$

Perchloric acid was used to adjust the $\mathrm{pH}$ of test solutions, in order to obtain nitrosation reaction at $\mathrm{pH} 2.3$, and ensure the presence of BGE anion in the sample. ${ }^{43}$ According to Whatley, ${ }^{43}$ the presence of BGE ions in the sample solution avoids high resistance across a plug of nearly pure water, avoiding localized heating. Despites perchloric acid being reactive and dangerously corrosive, we used a highly diluted solution (concentration of $0.1 \% \mathrm{v} / \mathrm{v})$. After incubation, $\beta$-alanine was added to increase the $\mathrm{pH}$ and ensure the presence of nitrite in ionic form (88\%, calculated by PeakMaster 5.3).

According to Williams, ${ }^{14}$ nitrous acid decomposes to nitric oxide, nitric acid and water (equation 10), which was first elucidated by Abel and Schmidtz ${ }^{44}$ in 1928 (equations 11 and 12).

$$
\begin{aligned}
& 3 \mathrm{HNO}_{2} \rightarrow 2 \mathrm{NO}+\mathrm{NO}_{3}^{-}+\mathrm{H}_{3} \mathrm{O}^{+} \\
& 2 \mathrm{HNO}_{2} \rightleftharpoons \mathrm{NO}+\mathrm{NO}_{2}+\mathrm{H}_{2} \mathrm{O} \\
& 2 \mathrm{NO}_{2}+2 \mathrm{H}_{2} \mathrm{O} \rightleftharpoons \mathrm{HNO}_{2}+\mathrm{NO}_{3}^{-}+\mathrm{H}_{3} \mathrm{O}^{+}
\end{aligned}
$$

The experiments showed the presence of a nitrate peak, mainly in the control analysis, generated from nitrous acid decomposition. Chacuk et al. also highlighted, ${ }^{20}$ as described by Damschen and Martin, ${ }^{45}$ that nitrous acid is oxidized to nitric acid in the presence of $\mathrm{O}_{2}$ (equation 13), leading us to partially remove dissolved oxygen from the water to ensure the highest concentration of nitrous acid in solution.

$$
2 \mathrm{HNO}_{2}+\mathrm{O}_{2} \rightarrow 2 \mathrm{HNO}_{3}
$$

In previous studies, including the work by $\mathrm{Cox},{ }^{46}$ it 
Table 1. Parameters of merit of the optimized method for the quantification of nitrite to determine the AC of commercial teas using MISER

\begin{tabular}{|c|c|}
\hline Parameter of merit & Nitrite \\
\hline Linearity, calibration range / $\left(\mathrm{mg} \mathrm{L}^{-1}\right)$ & $5.0-35.0$ \\
\hline Linearity, slope ${ }^{\mathrm{a}}$ ( $\left.\mathrm{L} \mathrm{mg}^{-1}\right)$ & 0.11825 \\
\hline Slope standard deviation ${ }^{\mathrm{a}}$ & 0.00064 \\
\hline Linearity, intercept ${ }^{\mathrm{a}}$ & 0.0686 \\
\hline Intercept standard deviation ${ }^{\mathrm{a}}$ & 0.0116 \\
\hline Linearity, coefficient of determination $\left(\mathrm{R}^{2}\right)^{\mathrm{a}}$ & 0.9991 \\
\hline Limit of detection $(\mathrm{LOD})^{\mathrm{b}} /\left(\mathrm{mg} \mathrm{L}^{-1}\right)$ & 0.324 \\
\hline Limit of quantification (LOQ) $)^{\mathrm{b}} /\left(\mathrm{mg} \mathrm{L}^{-1}\right)$ & 0.981 \\
\hline Instrumental precision, RSD, peak $\operatorname{area}^{c} / \%$ & 0.78 \\
\hline Instrumental precision, RSD, migration time ${ }^{\mathrm{c}} / \%$ & 1.59 \\
\hline $\begin{array}{l}\text { Instrumental precision, RSD, corrected migration } \\
\text { time } / \%\end{array}$ & 0.58 \\
\hline Intra-day precision, RSD, peak $\operatorname{area}^{c} / \%$ & 2.21 \\
\hline Intra-day precision, RSD, migration time ${ }^{c} / \%$ & 0.94 \\
\hline $\begin{array}{l}\text { Intra-day precision, RSD, corrected migration } \\
\text { time } / \%\end{array}$ & 0.32 \\
\hline Inter-day precision, RSD, peak area / \% & 1.98 \\
\hline Inter-day precision, RSD, migration time $/ \%$ & 3.06 \\
\hline $\begin{array}{l}\text { Inter-day precision, RSD, corrected migration } \\
\text { time } / \%\end{array}$ & 0.71 \\
\hline Number of plates $/\left(\mathrm{N} \mathrm{m}^{-1}\right)$ & $82,000-136,000$ \\
\hline Resolution (analyte:internal standard) ${ }^{\mathrm{e}}$ & $1.30-1.67$ \\
\hline \multicolumn{2}{|c|}{ 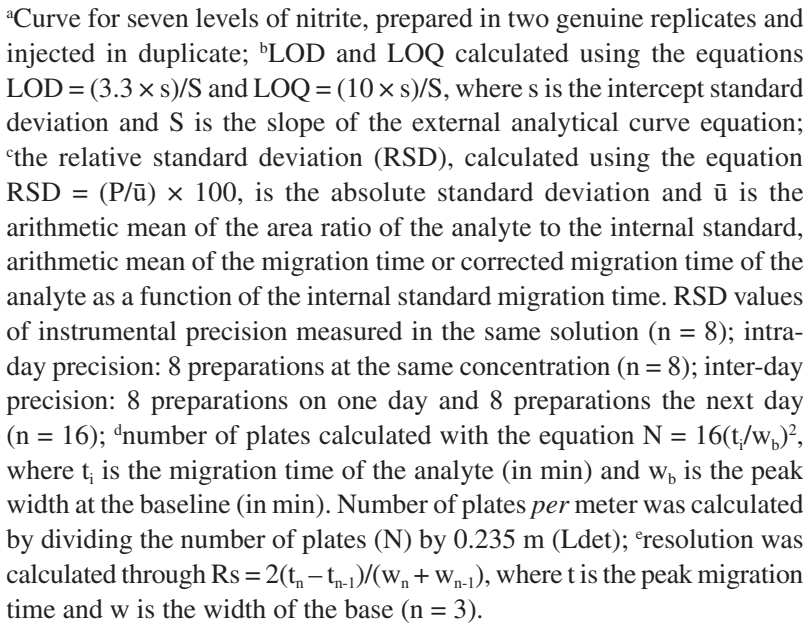 } \\
\hline
\end{tabular}

was found that the photolysis of nitrous acid results in hydroxyl radicals. ${ }^{47}$ Thus, the reactions were carried out in amber vials to ensure the absence of light and prevent the photolysis of nitrous acid, increasing the concentration of nitrite.

DNA bases, such as adenine, cytosine, 5-methylcytosine and guanine, are susceptible to damage by nitrosative deamination attributed to $\mathrm{N}_{2} \mathrm{O}_{3}$, which can lead to mutagenesis. ${ }^{48-52} \mathrm{~A}$ study conducted by Oldreive et al ${ }^{53}$ demonstrated the inhibition of base deamination by plant phenolics, particularly epigallocatechin gallate.

\section{Sample analysis}

In order to demonstrate that tea solutions are interferencefree, tea analysis was carried out. Figure 2 shows black tea sample electropherogram (plus internal standard) and black tea sample added to nitrite and internal standard, before and after incubation period. In the presence of black tea, nitrite peak decreases significantly after $60 \mathrm{~min}$ of incubation.

Figures 3 and 4 illustrate boldo tea and chamomile tea electropherograms, respectively.

The samples with the strongest AC were black tea, green tea and white tea (Table 2), which are produced from leaves of Camellia sinensis. ${ }^{54}$ Boldo, mint and strawberry teas showed moderate antinitrosating capacity. A concentration-response trend was observed, since the $\mathrm{AC}$ increased with increasing concentrations of tea. An antinitrosating effect can be useful to avoid nitrosamine health risks, especially considering the favorable formation of nitrosamines in the stomach (under acidic conditions)..$^{55}$ According to Carloni et al. ${ }^{56}$ green tea, black tea and white tea contain phenolic compounds, including catechins, such as (+)-catechin, (-)-epigallocatechin, (-)-epigallocatechin gallate and (-)-epicatechin gallate. Jeszka-Skowron and Zgoła-Grześkowiak ${ }^{57}$ also noted the presence of rutin, quercetin, gallic acid, chlorogenic acid, protocatechuic acid, $p$-coumaric acid, caffeic acid, ferulic acid and syringic acid.

The AC of these samples may be associated with the presence of $(+)$-catechin and (-)-epicatechin, as reported by Choi et al., ${ }^{22}$ who also noted the potent AC of caffeic acid and quercetin. Studies conducted by Masuda et al. ${ }^{58}$ and Tanaka et al. ${ }^{59}$ showed a significant inhibition of the formation of nitrosamines in the presence of highly concentrated green tea containing catechins. A correlation between green tea and black tea as inhibitors of $\mathrm{N}$-nitrosation and their phenolic contents was demonstrated by Wu et al. ${ }^{60}$

\section{Conclusions}

MISER presents several advantages, including the decreasing of total time and allowing the direct detection of nitrite, which eliminates the need for the Griess reaction step. In the results obtained in this study, the most potent $\mathrm{AC}$ of the teas was observed when catechins are present. This study highlights the importance of these herbal teas as sources of antinitrosating substances and their potential health benefits. 
(a)
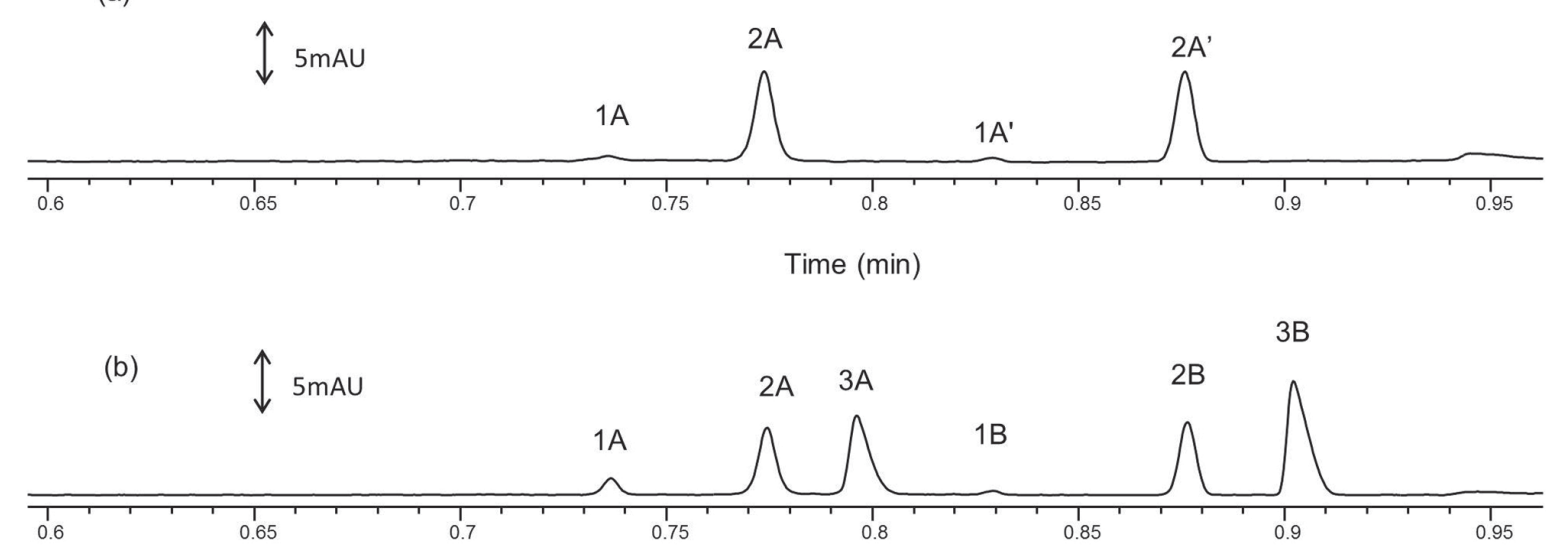

Time $(\min )$

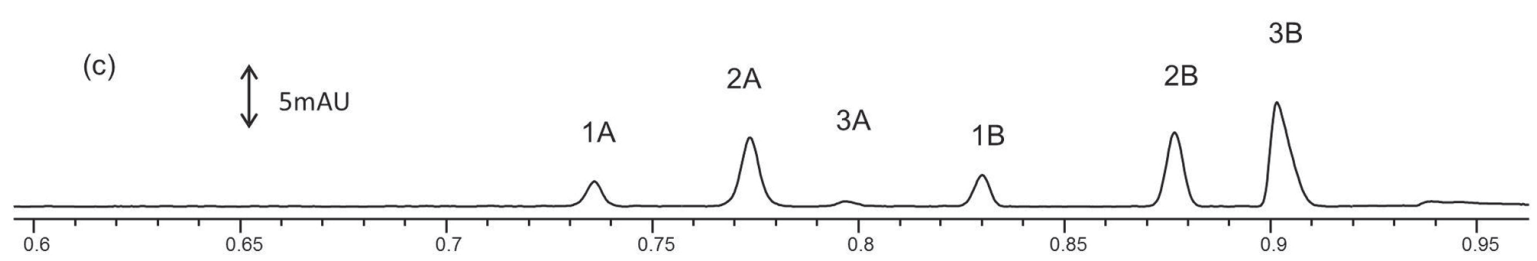

Time (min)

Figure 2. Comparison of MISER injection for black tea (plus IS) (a) and black tea and nitrite (plus IS) before incubation (b) and after incubation time (c). Peaks: 1: nitrate; 2: thiocyanate (IS); 3: nitrite; A, A' and B represent the first sample injection, second sample injection and control injection, respectively. Experimental conditions: capillary $32.0 \mathrm{~cm}$ (effective length $23.5 \mathrm{~cm}) \times 50 \mu \mathrm{m}$; BGE $4.0 \mathrm{~g} \mathrm{~L}^{-1} \beta$-alanine and $1.5 \mathrm{~g} \mathrm{~L}^{-1}$ perchloric acid, at $\mathrm{pH} 3.79$, voltage $-30 \mathrm{kV}, 25^{\circ} \mathrm{C}$.

(a)

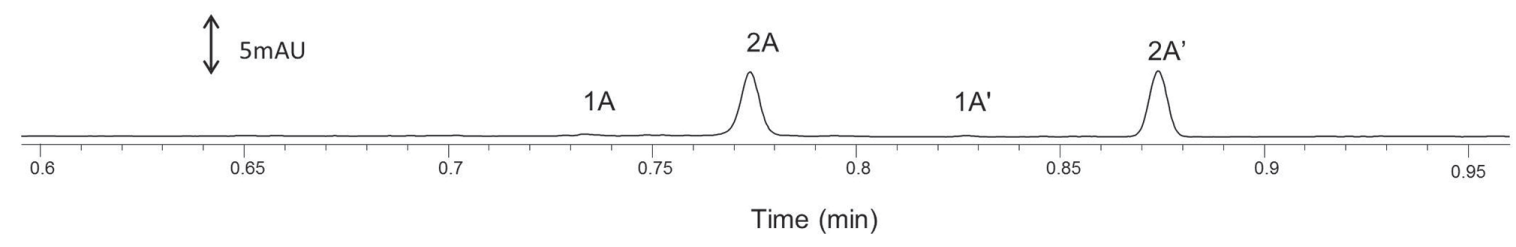

(b)

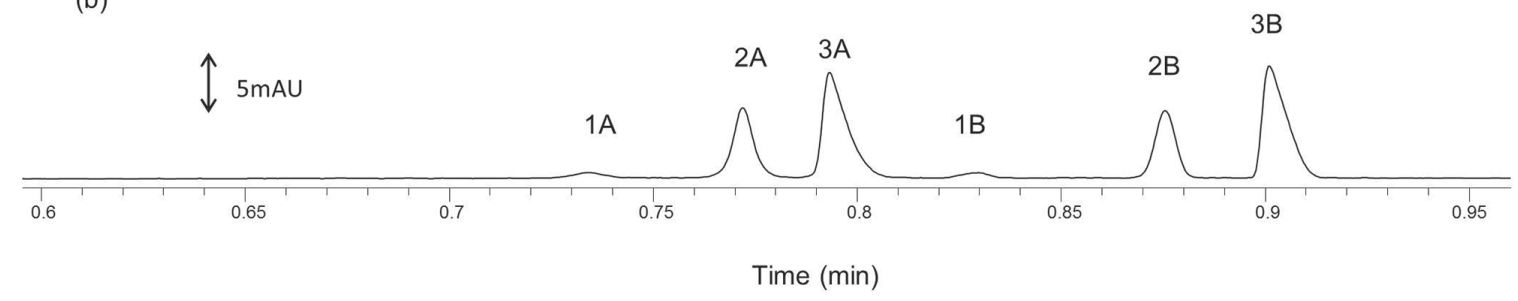

(c)

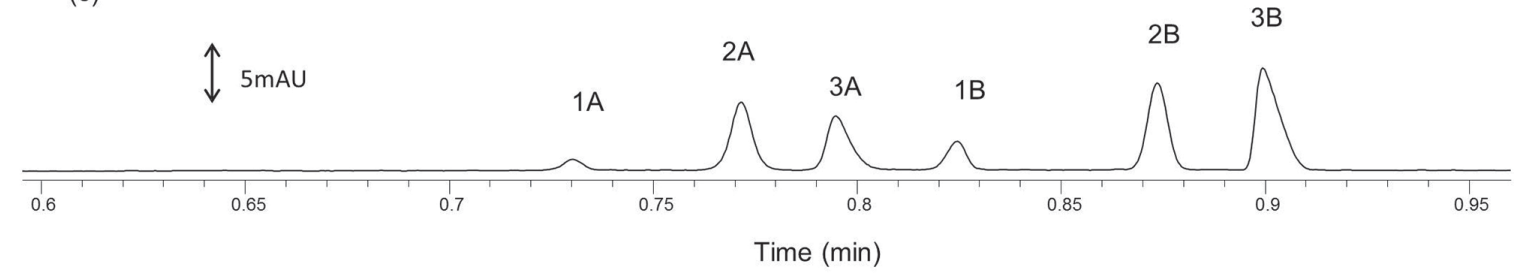

Figure 3. Comparison of MISER injection for boldo tea (plus IS) (a) and boldo tea and nitrite (plus IS) before incubation (b) and after incubation time (c). Peaks: 1: nitrate; 2: thiocyanate (IS); 3: nitrite; A, A' and B represent the first sample injection, second sample injection and control injection, respectively. Experimental conditions: capillary $32.0 \mathrm{~cm}$ (effective length $23.5 \mathrm{~cm}$ ) $\times 50 \mu \mathrm{m}$; BGE $4.0 \mathrm{~g} \mathrm{~L}^{-1} \beta$-alanine and $1.5 \mathrm{~g} \mathrm{~L}^{-1}$ perchloric acid, at $\mathrm{pH} 3.79$, voltage $-30 \mathrm{kV}, 25^{\circ} \mathrm{C}$. 


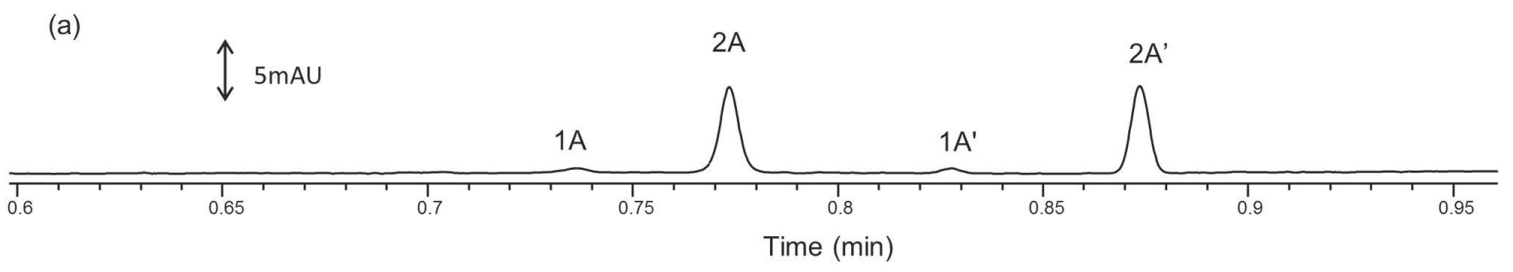

(b)

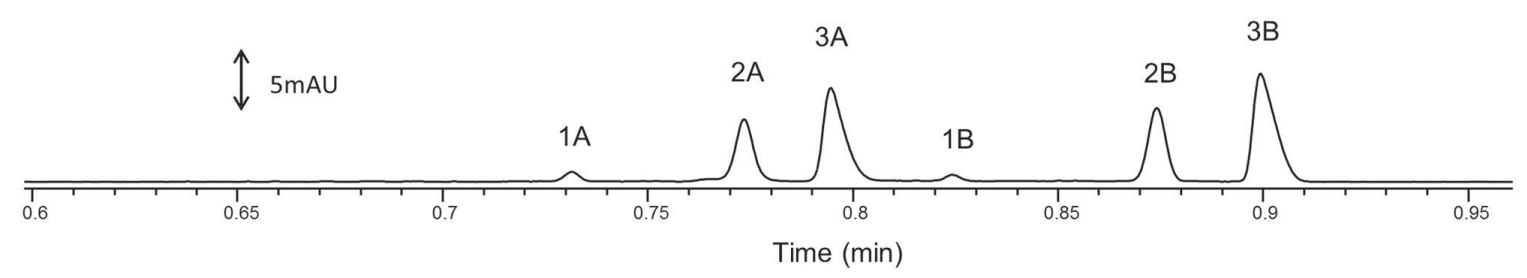

(c)

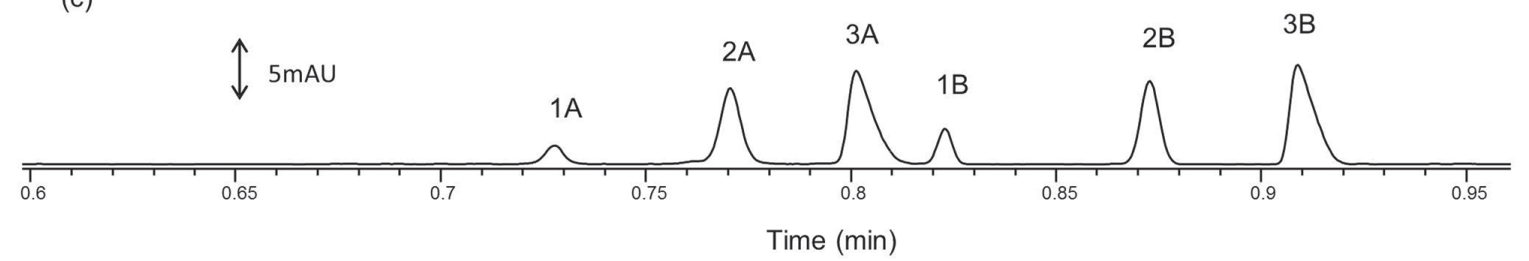

Figure 4. Comparison of MISER injection for chamomile tea (plus IS) (a) and chamomile tea and nitrite (plus IS) before incubation (b) and after incubation time(c). Peaks: 1: nitrate; 2: thiocyanate (IS); 3: nitrite; A, A' and B represent the first sample injection, second sample injection and control injection, respectively. Experimental conditions: capillary $32.0 \mathrm{~cm}$ (effective length $23.5 \mathrm{~cm}$ ) $\times 50 \mu \mathrm{m}$; BGE $4.0 \mathrm{~g} \mathrm{~L}^{-1} \beta$-alanine and $1.5 \mathrm{~g} \mathrm{~L} \mathrm{~L}^{-1}$ perchloric acid, at $\mathrm{pH} 3.79$, voltage $-30 \mathrm{kV}, 25^{\circ} \mathrm{C}$.

Table 2. Antinitrosating capacity (AC) of commercial teas

\begin{tabular}{lc}
\hline Tea & AC / \% \\
\hline Black & $96 \pm 1$ \\
Boldo & $44 \pm 2$ \\
Chamomile & $8 \pm 1$ \\
Detox & $14 \pm 2$ \\
Fennel & $7 \pm 1$ \\
Green & $93 \pm 1$ \\
Mint & $37 \pm 1$ \\
Strawberry & $40 \pm 1$ \\
White & $89 \pm 1$ \\
\hline
\end{tabular}

\section{Acknowledgments}

The authors acknowledge CNPq, CAPES and INCTCatálise for financial support.

\section{References}

1. Froehlich, D. A.; Gullett, E. A.; Usborne, W. R.; J. Food Sci. 1988, 48,152 .

2. Merino, L.; Örnemark, U.; Toldrá, F.; Adv. Food Nutr. Res. 2017, 81,65 .
3. Yetim, H.; Kayacier, A.; Kesmen, Z.; Sagdic, O.; Meat Sci. 2006, 72, 206.

4. Bartsch, H.; Ohshima, H.; Pignatelli, B.; Mutat. Res. 1988, 202, 307.

5. Sun, J.; He, X.; Zhao, M.; Li, L.; Li, C.; Dong, Y.; Molecules 2014, 19, 13147.

6. Virtanen, S. M.; Jaakkola, L.; Räsänen, L.; Ylönen, K.; Aro, A.; Lounamaa, R.; Akerblom, H. K.; Tuomilehto, J.; Diabetic Med. 1994, 11, 656.

7. Xie, L.; Mo, M.; Jia, H. X.; Liang, J.; Zhu, J.; Oncotarget 2016, 30,56915 .

8. Honikel, K. O.; Meat Sci. 2008, 78, 68.

9. European Parliament and Council Directive 95/2/EC; Additives other than Authorised Colours and Sweeteners; Official Journal of the European Union: Brussels, 1995, L 061, p. 0001-0040.

10. Lee, H.; Food Addit. Contam., Part A 2018, 35, 29.

11. DellaValle, C. T.; Xiao, Q.; Yang, G.; Shu, X. O.; AschebookKilfoy, B.; Zheng, W.; Li, H. L.; Ji, B. T.; Rothman, N.; Chow, W. H.; Gao, Y. T.; Ward, M. H.; Int. J. Cancer 2014, 15, 2917.

12. Sebranek, J. G.; Fox Jr., J. B.; J. Sci. Food Agric. 1985, 36, 1169.

13. González-Mancebo, S.; García-Santos, M. P.; HernándezBenito, J.; Calle, E.; Casado, J.; J. Agric. Food Chem. 1999, 47, 2235. 
14. Williams, D. L. H.; Nitrosation Reactions and the Chemistry of Nitric Oxide, $1^{\text {st }}$ ed.; Elsevier BV: Amsterdam, The Netherlands, 2004.

15. Challis, B. C.; Kyrtopoulos, S. A.; J. Chem. Soc., Perkin Trans. 1 1979, 2, 299.

16. Challis, B. C.; Shuker, D. E. G.; Food Cosmet. Toxicol. 1980 , $18,283$.

17. Choi, J.; Valentine, R. L.; Environ. Sci. Technol. 2003, 37, 4871.

18. Lewis, R. S.; Tannenbaum, S. R.; Deen, W. M.; J. Am. Chem. Soc. 1995, 117, 3933.

19. Ignarro, L. T.; Fukuto, J. M.; Griscavage, J. M.; Rogers, N. E.; Byrns, R. E.; Proc. Natl. Acad. Sci. U. S. A. 1993, 90, 8103.

20. Chacuk, A.; Miller, J. S.; Wilk, M.; Ledakowicz, S.; Chem. Eng. Sci. 2007, 62, 7446.

21. Liu, J.; Lin, S.; Wang, Z.; Wang, C.; Wang, E.; Zhang, Y.; Liu, J.; Food Bioprod. Process. 2011, 89, 333.

22. Choi, J. S.; Park, S. H.; Choi, J.; Arch. Pharm. Res. 1989, 12, 26.

23. Kato, T.; Kikugawa, K.; Food Chem. Toxicol. 1992, 30, 617.

24. Cotelle, P.; Vezin, H.; Tetrahedron Lett. 2001, 42, 3303.

25. Wang, Y.; Li, F.; Zhuang, H.; Chen, X.; Li, L.; Qiao, W.; Zhang, J.; LWT - Food Sci. Technol. 2015, 60, 199.

26. Chung, M. J.; Lee, S. H.; Sung, N. J.; Cancer Lett. 2002, 182, 1.

27. Fan, T.; Tannenbaum, S. R.; J. Agric. Food Chem. 1971, 19, 1267.

28. Bhakta, S. A.; Borba, R.; Taba Jr., M.; Garcia, C. D.; Carrilho, E.; Anal. Chim. Acta 2014, 809, 117.

29. Moorcroft, M. J.; Davis, J.; Compton, R. G.; Talanta 2001, 54, 785.

30. Wang, Q.; Yu, L.; Yang, L.; Lin, L.; Lu, R.; Zhu, J.; He, L.; Lu, Z.; Talanta 2017, 165, 709.

31. Valese, A. C.; Spudeit, D. A.; Dolzan, M. D.; Bretanha, L. C.; Vitali, L.; Micke, G. A.; J. Anal. Methods Chem. 2016, 2016, DOI 10.1155/2016/4126810.

32. Kovács, Z.; Szarka, M.; Szigeti, M.; Guttman, A.; J. Pharm. Biomed. Anal. 2016, 128, 367.

33. Amini, A.; Lodén, H.; Pettersson, C.; Arvidsson, T.; Electrophoresis 2008, 29, 3952.

34. Costa, A. S. G.; Nunes, M. A.; Almeida, I. M. C.; Carvalho, M. R.; Barroso, M. F.; Alves, R. C.; Oliveira, M. B. P. P.; LWT - Food Sci. Technol. 2012, 49, 324.

35. Jin, L.; Li, X.; Tian, D.; Fang, X.; Yu, Y.; Zhu, H.; Ge, Y.; Ma, G.; Wang, W.; Xiao, W.; Li, M.; Ind. Crops Prod. 2016, 87, 198.

36. Spudeit, D. A.; Gonçalves, S.; Bretanha, L. C.; Claumann, C. A.; Machado, R. A. F.; Micke, G. A.; J. Braz. Chem. Soc. 2016, 27, 1974.

37. Della Betta, F.; Vitali, L.; Fett, R.; Costa, A. C. O.; Talanta 2014, 122, 23.

38. Melanson, J. E.; Lucy, C. A.; J. Chromatogr. A 2000, 884, 311.
39. Vitali, L.; Della Betta, F.; Costa, A. C. O.; Vaz, F. A. S.; Oliveira, M. A. L.; Vistuba, J. P.; Fávere, V. T.; Micke, G. A.; Talanta $\mathbf{2 0 1 4}, 123,45$.

40. Hruska, V.; Riesova, M.; Gas, B.; Electrophoresis 2012, 33, 923.

41. Choi, S. Y.; Chung, M. J.; Seo, W. D.; Shin, J. H.; Shon, M. Y.; Sung, N. J.; J. Agric. Food Chem. 2006, 54, 6075.

42. Mirvish, S. S.; Toxicol. Appl. Pharmacol. 1975, 31, 325.

43. Whatley, H. In Clinical and Forensic Applications of Capillary Electrophoresis; Petersen, J. R.; Mohammad, A. A., eds.; Humana Press: Totowa, USA, 2001, ch. 2.

44. Abel, E.; Schmidtz, H.; Z. Phys. Chem. 1928, 134, 279.

45. Damschen, D. E.; Martin, L. R.; Atmos. Environ. (1967) 1983, 17, 2005.

46. Cox, A.; J. Photochem. 1974, 3, 175.

47. Cheng, P.; Cheng, Y.; Lu, K.; Su, H.; Yang, Q.; Zou, Y.; Zhao, Y.; Dong, H.; Zeng, L.; Zhang, Y.; J. Environ. Sci. 2013, 25, 895.

48. Burney, S.; Caulfield, J. L.; Niles, J. C.; Wishnok, J. S.; Tannenbaum, S. R.; Mutat. Res. 1999, 424, 37.

49. Shapiro, R.; Pohl, S. H.; Biochemistry 1968, 7, 448.

50. Caulfield, J. L.; Wishnok, J. S.; Tannenbaum, S. R.; J. Biol. Chem. 1998, 273, 12689.

51. Tannenbaum, S. R.; Tamir, S.; Rojas-Walker, T.; Wishnok, J. S. In Nitrosamines and Related N-Nitroso Compounds: Chemistry and Biochemistry; Loeppky, L. N.; Michejda, C. J., eds.; American Chemical Society: Washington, DC, USA, 1994, ch. 10.

52. Wink, D. A.; Kasprzak, K. S.; Maragos, C. M.; Elespuru, R. K.; Misra, M.; Dunams, T. M.; Cebula, T. A.; Koch, W. H.; Andrews, A. W.; Allen, J. S.; Keefer, L. K.; Science 1991, 254, 1001.

53. Oldreive, C.; Zhao, K.; Paganga, G.; Halliwell, B.; Rice-Evans, C.; Chem. Res. Toxicol. 1998, 11, 1574.

54. Tan, J.; Engelhardt, U. H.; Lin, Z.; Kaiser, N.; Maiwald, B.; J. Food Compos. Anal. 2017, 57, 8.

55. Bedale, W.; Sindelar, J. J.; Milkowski, A. L.; Meat Sci. 2016, 120,85 .

56. Carloni, P.; Tiano, L.; Padella, L.; Bacchetti, T.; Customu, C.; Kay, A.; Damiani, E.; Food Res. Int. 2013, 53, 900.

57. Jeszka-Skowron, M.; Zgoła-Grześkowiak, A.; Food Anal. Methods 2014, 7, 2033.

58. Masuda, S.; Uchida, S.; Terashima, Y.; Kuramoto, H.; Serizawa, M.; Deguchi, Y.; Yanai, K.; Sugiyama, C.; Oguni, I.; Kinae, N.; J. Health Sci. 2006, 52, 211.

59. Tanaka, K.; Hayatsu, T.; Negishi, T.; Hayatsu, H.; Mutat. Res. 1998, 412, 91.

60. Wu, Y. N.; Wang, H. Z.; Li, J. S.; Han, C.; Biomed. Environ. Sci. 1993, 6, 237.

Submitted: February 20, 2018

Published online: May 10, 2018 